\title{
THE ROLE OF THE PHOSPHOINOSITIDE PATHWAY IN HORMONAL REGULATION OF THE EPITHELIAL SODIUM CHANNEL
}

\author{
Bonnie L. Blazer-Yost and Charity Nofziger*
}

\section{INTRODUCTION}

The phosphoinositide (PI) pathway, initiated by the activation of phosphatidylinositol 3-kinase (PI3-kinase), forms a complex, branching signal transduction mechanism involving multiple lipids and protein kinases. This pathway has been implicated in the regulation of a wide variety of cellular processes including inhibition of apoptosis, stimulation of protein synthesis, cellular trafficking, actin rearrangement, and multiple transport processes. The pathway can be activated either by hormone dependent or independent signals and may be present in a constitutively active, tonic level in some cell types.

Our laboratory was the first to show that the PI pathway is crucial for both aldosterone (steroid) and insulin (peptide) hormone stimulation of renal $\mathrm{Na}^{+}$reabsorption. ${ }^{1-3}$ Subsequent work by us and others have solidified the importance of several of the components of the pathway in the natriferic $\left(\mathrm{Na}^{+}\right.$retaining) actions of the hormones.

\section{THE AMILORIDE-SENSITIVE $\mathrm{Na}^{+}$CHANNEL}

Epithelial $\mathrm{Na}^{+}$channels (ENaCs) are intimately involved in fluid and electrolyte homeostasis. These amiloride-sensitive channels are found in the apical membrane of a variety of salt-absorbing epithelia and form the rate-limiting step for $\mathrm{Na}^{+}$reabsorption. The importance of this channel in regulating $\mathrm{Na}^{+}$homeostasis is underscored by the number of steroid and peptide hormones which directly modulate channel activity in vivo, including aldosterone, insulin, ADH (anti-diuretic hormone), and IGF1 (insulin-like growth factor 1$).^{1-8}$

The primary components of the channel have been described at a molecular level. ${ }^{9-11}$

\footnotetext{
* Bonnie L. Blazer-Yost and Charity Nofziger, Biology Dept., Indiana University Purdue University at Indianapolis, Indianapolis, Indiana, 46202.
} 
The basic building blocks consist of homologous subunits termed $\alpha, \beta$, and $\gamma$. $\alpha$ is required and sufficient for transport albeit at a low level. ${ }^{9,11}$ In the oocyte expression system, neither the $\beta$ nor $\gamma$ subunit alone can confer $\mathrm{Na}^{+}$transport to the oocyte. However, co-expression of all three subunits leads to a 10-100 fold increase in transport as compared to rates of transport seen with the expression of $\alpha$ alone. ${ }^{10}$

Clinically, mutations in the C-terminal region of the $\beta$ or $\gamma$ subunit can cause Liddles syndrome, a severe form of hypertension resulting from constitutive activation of the renal ENaC. ${ }^{12,13}$ Mutations in $\alpha$ as well as amino acid substitutions in either the cytoplasmic N-terminal portion of $\beta$ or the extracellular region of $\gamma$ result in pseudohypoaldosteronism type 1 , characterized by renal salt wasting and hyperkalemic metabolic acidosis due to loss of channel activity. ${ }^{14-16}$ These clinical observations support the principle that $\mathrm{ENaC}$ is crucial for regulation of salt and water homeostasis and that mutations in the channel, particularly in the cytoplasmic domains, cause serious disturbances in the maintenance of this delicate balance.

One of the most common clinical entities arising from an imbalance of salt and water homeostasis is essential hypertension. Based on the findings of the most recent National Health and Nutrition Examination Survey (NHANES) collected from 1999-2000, 28.7\% of the U.S. adult population had hypertension. ${ }^{17}$ This is an alarming increase compared to the NHANES study from 1988 through 1991 which indicated $24 \%$ of adults had hypertension. ${ }^{18}$ The development of essential hypertension is a multifactorial pathogenic process. Clearly, there are both genetic and environmental influences. However, many of the predisposing factors, e.g., aberrations in the renin-angiotensin-aldosterone axis; hyperinsulinemia, have the common result of stimulating $\mathrm{Na}^{+}$reabsorption in the renal distal tubule/collecting duct via a direct effect on the ENaC. Understanding the regulatory mechanisms controlling $\mathrm{ENaC}$ activity is, therefore, an essential prerequisite to designing therapeutic modalities aimed at controlling disturbances in fluid and electrolyte balance such as hypertension.

\section{HORMONAL REGULATION OF ENaC}

The three hormonal systems that regulate $\mathrm{ENaC}$ activity in the principal cells of the distal nephron - aldosterone, insulin, and $\mathrm{ADH}$ - have additive or synergistic actions, one to another, on the $\mathrm{Na}^{+}$reabsorptive transport process. Therefore, it follows that there are individual and distinct rate-limiting steps between receptor binding and channel activation.

Renal $\mathrm{Na}^{+}$retention can be attained by increasing the density of active ENaCs in the apical membrane, by increasing the open probability of individual channels, or by altering single channel current. In all studies to date, the single channel current appears to vary according to the electrochemical driving forces across the apical membrane rather than in response to direct hormonal stimulation. Interestingly, using blocker-induced noise analysis, we have found that both insulin and aldosterone cause an increase in the number of active channels in the apical membrane with no increase in the open probability of the channel. ${ }^{2,6}$ Previous noise analysis studies by Els and Helman have shown that the action of ADH also involves an increase in the number of active channels in the apical membrane. ${ }^{19}$ These studies are in direct contrast to those using patch clamp techniques where investigators have found an increase in open probability in response to both 
insulin and aldosterone. ${ }^{20,21}$ Reasons for this discrepancy are not immediately obvious, although, there may be some contribution from the invasive nature of the patch clamp technique.

In order to resolve the controversy, we stably transfected green fluorescent protein (GFP)-tagged $\mathrm{ENaC}$ subunits into model renal epithelial cells and demonstrated that the labeled channels were indeed functional. ${ }^{8}$ Using the transfected lines, we were able to confirm, in the case of ADH and insulin, a movement of labeled channel from an internal pool into the apical plasma membrane, thus substantiating the noise analysis data. ${ }^{2,6,8}$ The combined data provide strong support for the contention that the actions of all three hormones appear to culminate in the insertion of $\mathrm{ENaC}$ into the apical membrane. Therefore, the discriminating, rate-limiting steps in the various pathways are proximal to the insertion reaction.

\section{PI3-KINASE}

The PI3-kinases are a family of enzymes which phosphorylate the D-3 position of the myo-inositol ring of phosphatidylinositols (PtdIns) and according to relative specificity, form $\mathrm{PI}(3) \mathrm{P}$ (phosphatidylinositol-3-phosphate), $\mathrm{PI}(3,4) \mathrm{P}_{2}$, or $\mathrm{PI}(3,4,5) \mathrm{P}_{3}{ }^{22-24}$ These kinases have been implicated as key regulatory components of a wide variety of cellular processes ${ }^{25-32}$ including peptide stimulated ion transport events. ${ }^{29-32}$

With regard to transporters, PI3-kinase activity has been shown to be involved in insulin-stimulated insertion of vesicles containing glucose transporters (GLUT4) into the membranes of adipocytes ${ }^{27}$ and skeletal muscle. ${ }^{28}$ More recently, other peptide hormonemediated transport events have been shown to be dependent on the production of $\mathrm{PIP}_{3}$. These include insulin-stimulated $\mathrm{K}^{+}$uptake into fibroblasts via the $\mathrm{Na}^{+} / \mathrm{K}^{+} / 2 \mathrm{Cl}^{-}$ cotransporter, ${ }^{29}$ PDGF (platelet-derived growth factor) activation of the $\mathrm{Na}^{+} / \mathrm{H}^{+}$ exchanger, ${ }^{30}$ EGF (epidermal growth factor) stimulation of intestinal $\mathrm{Na}^{+}$absorption, ${ }^{31}$ and EGF-mediated inhibition of $\mathrm{Ca}^{2+}$-dependent $\mathrm{Cl}^{-}$secretion. ${ }^{32}$

We have previously identified PI3-kinase as a regulator of basal, aldosterone- and insulin-stimulated $\mathrm{Na}^{+}$flux. ${ }^{1-3}$ Hormone induced increases in the enzyme activity have been demonstrated in model renal cell lines, and this heightened activity is directly correlated with changes in $\mathrm{Na}^{+}$transport. Thus, the phosphoinositide pathway appears to form a central control point in the regulation of both peptide- and steroid-mediated natriferic activity (Figure 1).

Specifically, in the A6 cell culture model of the principal cells of the distal nephron, we have shown that stimulation with either insulin or aldosterone results in an increase of $\mathrm{PIP}_{3}$. In addition, basal, insulin-stimulated and aldosterone-stimulated $\mathrm{Na}^{+}$transport are all abolished by LY294002, a specific inhibitor of PI3-kinase. ${ }^{1,2}$ These results indicate that both hormones have an effect on the activity of the enzyme and that this stimulation of activity is necessary for insulin and aldosterone-stimulated $\mathrm{Na}^{+}$retention.

The insulin results were not unanticipated because this peptide hormone is known to activate PI3-kinase via the insulin receptor substrate (IRS) signaling intermediate in other tissues. However, the pathway stimulated in response to insulin binding in these polarized cells may be different than that described in non-polarized tissues. We have demonstrated that in response to insulin, $\mathrm{ENaC}$ moves from a diffuse cytoplasmic localization to the apical and lateral membranes. Co-localization studies have shown that $\mathrm{ENaC}$ and PI3-kinase are not co-localized under basal conditions. Rather, the two entities 
co-localize and are mobilized along the lateral membrane within one minute of insulin stimulation. ${ }^{3}$ These data indicate that insulin stimulates the migration of $\mathrm{ENaC}$ into the apical membrane and that this trafficking is dependent on PI3-kinase activity. The details of the trafficking pathway remain unresolved but will be of interest because they appear to be mediated by a heretofore undescribed trafficking route for integral membrane proteins in polarized epithelial cells.

Our results with regard to the importance of PI3-kinase in aldosterone's action were rather surprising. Steroid hormone regulation of ion transport had not been previously linked to the PI pathway. The aldosterone stimulated increase in $\mathrm{PIP}_{3}$ indicates that there is a steroid hormone-stimulated event at or before PI3-kinase which may modify the amount and/or activity of the enzyme. The identification of this portion of the signaling pathway will be important as it is a likely site for the first rate-limiting step in aldosterone's natriferic action.

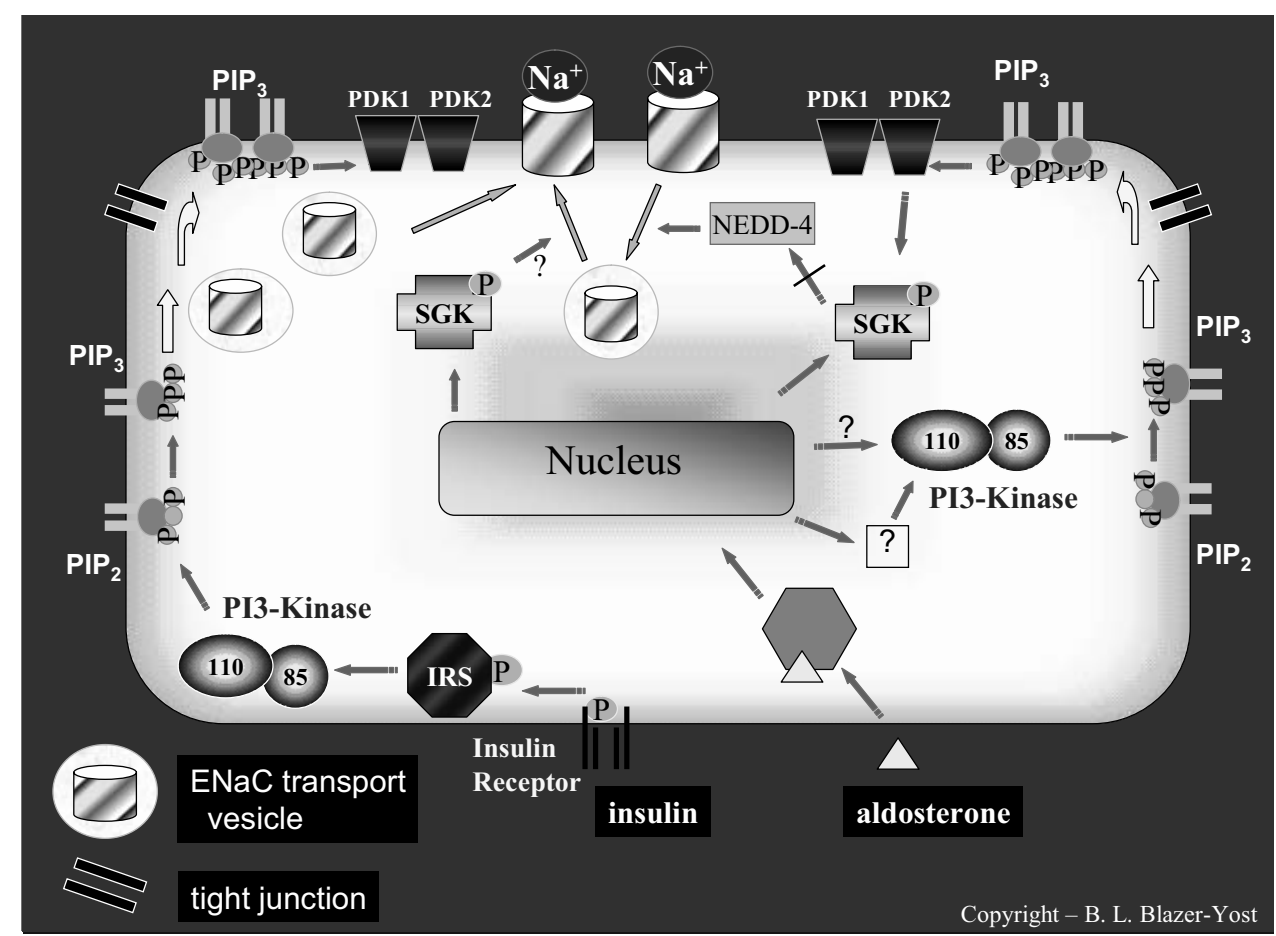

Figure 1: Working hypothesis of the signal transduction pathway followed by natriferic hormones which stimulate transcellular $\mathrm{Na}^{+}$transport in the principal cell of the mammalian distal nephron. This theoretical model reflects the pathways discussed in the text. $\mathrm{ENaC}=$ epithelial $\mathrm{Na}^{+}$channel; IRS $=$insulin receptor substrate; $\mathrm{PIP}_{2}=$ phosphatidylinositol-4,5-bisphosphate; $\mathrm{PIP}_{3}=$ phosphatidylinositol-3,4,5-trisphosphate; sgk = serum, glucocorticoid-induced kinase; PDK = phosphatidylinositide-dependent kinase; NEDD-4 = neuronal precursor cell developmentally downregulated gene 4 . 
PI3-kinase-mediated phosphorylation of the inositol headgroup of $\mathrm{PIP}_{2}$ stimulates the activity of the serine/threonine kinases, phosphoinositide-dependent kinases (PDK) 1 and $2{ }^{33,34}$ There are a number of substrates for the PDKs which have been identified. Several have been shown to be involved in transport events, particularly Akt (related to A and C kinase) also known as PKB (protein kinase B), ${ }^{33,}{ }^{34}$ PKA (cAMP-dependent protein kinase $\mathrm{A})^{5}$ and sgk (serum, glucocorticoid induced kinase). ${ }^{36,37}$ Of these, sgk has been shown to be a crucial regulatory component in hormone-stimulated $\mathrm{Na}^{+}$transport.

\section{SGK}

Sgk, Akt and PKA all belong to the same "family" of serine/threonine kinases linked by a structural similarity in the kinase domain, particularly the activation loop. Within the activation loop, PDK1 phosphorylation of a key threonine residue is necessary for enzyme activation. The particular motif defining the single PDK1 phosphorylation site is common to these three serine/threonine kinases. ${ }^{3,35-37}$ Phosphorylation of these substrates by PDK2 on a serine residue outside the activation loop appears to have a permissive effect on activity.

Of the PDK substrates, sgk is potentially the most interesting because it has been shown to be an aldosterone-induced protein in A6 epithelia ${ }^{38}$ and rat cortical collecting ducts. ${ }^{39}$ This kinase is regulated by multiple factors including serum, steroid hormones and cell volume changes. When the mRNAs for sgk and $\mathrm{ENaC}$ are co-expressed in oocytes, the $\mathrm{ENaC}$ activity is potentiated several-fold. ${ }^{38,39}$

It has been demonstrated that sgk does not phosphorylate the channel per se. Interestingly, however, one of the substrates for the enzyme is an ENaC regulatory protein, a ubiquitin ligase termed Nedd4-2 (neural precursor cell-expressed, developmentally downregulated gene 4, isoform 2). ${ }^{40-42}$ Nedd4-2 has been shown to be an ENaC partner in a two hybrid system. ${ }^{41}$ The ubiquitin ligase contains WWW domains which bind the highly conserved proline-rich PY (proline-tyrosine) motifs in the carboxyl termini of $\mathrm{ENaC}$ subunits. In the kidney, Nedd4-2 has been immunolocalized to the cortical collecting tubules and outer and inner medullary collecting ducts. ${ }^{42}$ Nedd4-2 appears to be a negative regulator of $\mathrm{ENaC}$ which ubiquitinates the channel, thereby targeting it for endocytosis and, presumably, degradation. Sgk phosphorylation of Nedd4-2 inhibits the binding of this ubiquitin ligase to the channel, resulting in increased channel expression in the apical membrane. ${ }^{40,43-45}$ While expression of Nedd4-2 is not altered by elevations of serum aldosterone, ${ }^{42} \mathrm{sgk}$ which can negatively modulate its activity is an aldosteroneinduced protein. The role of sgk in this portion of the pathway could be envisioned as an inhibitor of the "turn-off" mechanism of aldosterone's action.

It is possible that sgk may play additional roles in the natriferic action of both steroid and peptide hormones. In native, $\mathrm{Na}^{+}$transporting epithelial cells (A6 cell line), we have supplemented the endogenous sgk by stably transfecting with either wt or mutated enzyme and have used the resultant cell lines to show that sgk plays a role in basal as well as insulin-, ADH- and aldosterone-stimulated $\mathrm{Na}^{+}$transport. ${ }^{46}$ The enzyme is required for basal and hormone-stimulated transport; a dominant negative form of the kinase abolishes all transepithelial $\mathrm{Na}^{+}$flux. Expression of additional wt sgk results in a potentiated response to ADH indicating that the enzyme is rate-limiting for this natriferic response. In contrast, the enzyme, while necessary, does not appear to be rate-limiting for insulin- or aldosterone-stimulated $\mathrm{Na}^{+}$transport. ${ }^{46}$ These studies are in agreement with a 
mouse sgk knock-out model demonstrating a milder phenotype than the corresponding ENaC or mineralocorticoid receptor knockout animals. ${ }^{47}$

Our results from the transfection studies have been substantiated by others who have reached the similar conclusion that sgk may also play a role in the initial steps of hormonal stimulation, possibly by mediating channel insertion into the membrane. ${ }^{48}$ In the search for a mechanism of the action of sgk in the initial steps of $\mathrm{Na}^{+}$channel activation, several intriguing clues have emerged. Alvarez de la Rosa and colleagues have found that in rat kidney, sgk1, the predominant isoform of the distal tubular cells, is expressed in relatively high amounts under basal conditions with little fluctuation in response to physiological concentrations of aldosterone. ${ }^{49} \mathrm{Sgk}$, a protein with no membrane spanning domains, was found associated with the microsomal fraction in tissue homogenates. Furthermore, sgk co-localized with $\mathrm{Na}^{+}, \mathrm{K}^{+}$-ATPase in immunohistochemical studies. ${ }^{49}$ These results suggest that sgk may be part of a complex found predominately on the basolateral membrane rather than on the apical membrane where sgk would be localized to regulate the ENaC/Nedd4-2 interaction.

As noted above, we have recently found that within one minute of insulin stimulation, $\mathrm{ENaC}$ moves first to the vicinity of the lateral membranes where it colocalizes with PI3-kinase, an enzyme that initiates a kinase cascade which can result in the activation of sgk. Subsequently, the $\mathrm{ENaC}$ enters the apical membrane. If the activity of PI3-kinase is inhibited with LY294002, ENaC and PI3-kinase still undergo an insulinmediated co-localization but are not trafficked to the lateral membrane, and ENaC does not enter the apical membrane. ${ }^{3}$ Given the sgk localization results cited above, it could be speculated that the entire PI pathway may be assembled in a complex close to the basolaterally-located peptide hormone receptors which initiate the natriferic signal. Confirmation of this speculation awaits experimental verification.

\section{INTERACTION BETWEEN THE PHOSPHOINOSITIDE AND CAMP/PKA PATHWAYS}

Biochemical pathways besides the PI pathway are capable of modulating changes in $\mathrm{Na}^{+}$reabsorption via ENaC. For example, ADH stimulates the cAMP/PKA signaling cascade via binding to a $\mathrm{V} 2$ receptor on the basolateral membrane of renal epithelial cells, thereby stimulating adenylate cyclase and the production of cAMP. The increased cAMP in turn activates PKA. The end result of the hormone-receptor binding is a decrease in $\mathrm{Na}^{+}$excretion but the post-PKA activation steps of the pathway remain unknown.

As cited above, sgk appears to be the rate-limiting step in $\mathrm{ADH}$-mediated $\mathrm{Na}^{+}$ reabsorption. ${ }^{46}$ Therefore, it is likely that the cAMP and PI pathways intersect. There are several plausible sites for this potential interaction. PKA and sgk are each substrates for PDK1 and 2. ${ }^{50,51}$ Thus, PKA could theoretically be modulated by the PI pathway in the absence of cAMP induction.

Alternatively, in the absence of PI3-kinase, the PKA pathway may activate downstream elements of the PI pathway. Sgk contains a PKA consensus sequence and Perrotti et al., have shown that 8-(4-chlorophenylthio)-cAMP caused a two-fold activation of $\mathrm{sgk}$ expressed in $\operatorname{COS} 7$ cells, ${ }^{52}$ indicating that cAMP can regulate sgk independently of PI3-kinase. This would be consistent with our observations that stimulation of A6 cells with ADH leads to an apparent potentiated response (measured as an increase in transport) if the PI3-kinase pathway has been inhibited by LY294002. ${ }^{53}$ 
One possible explanation for this finding is that the increased PKA activity could restore the sgk activity.

PKA and sgk can also phosphorylate the same substrate. Both kinases have been shown to regulate the ROMK channel, a $\mathrm{K}^{+}$leak channel activated in response to aldosterone stimulation, thereby causing it to be redistributed from the endoplasmic reticulum to the plasmolemma. ${ }^{54}$ Based on the latter findings, it would be reasonable to postulate that sgk and PKA may act on a novel, common substrate upstream of ENaC.

Clearly, the cAMP/PKA and PI pathways intersect. In model renal epithelial cells, both pathways regulate transepithelial $\mathrm{Na}^{+}$transport. Determining the site(s) of such complex interactions will require a melding of biochemical, electrophysiological, molecular and histological approaches.

\section{SUMMARY}

In summary, insulin and aldosterone stimulate phosphatidylinositol phosphorylation, thus indicating the existence of a regulated protein at or before the PI3-kinase step. ${ }^{1-5}$ Aldosterone induces the synthesis of sgk, a downstream element of the PI pathway. Sgk is necessary, but not rate-limiting, for aldosterone- and insulin-stimulated $\mathrm{Na}^{+}$transport. However, the enzyme appears to be rate-limiting for the natriferic action of ADH. Insulin-stimulated $\mathrm{Na}^{+}$transport, an acute response, is dependent on PI3-kinase activity but the magnitude of the response is not altered by a cellular excess of sgk. ADHstimulated transport is not dependent on PI3-kinase but is potentiated by an excess of sgk. The foregoing data indicate that the PI pathway is involved in several steps of the natriferic action of hormones and intersects with other pathways which regulate $\mathrm{ENaC}$. Furthermore, the data are consistent with the hypothesis that activation of PI3-kinase may ultimately stimulate channel insertion as well as regulate channel endocytosis. Both of these phenomena can result in an increase of ENaC-mediated $\mathrm{Na}^{+}$transport.

\section{REFERENCES}

1. R.D. Record, L.L. Froelich, C.J. Vlahos and B.L. Blazer-Yost, Phosphatidylinositol 3-kinase activation is required for insulin-stimulated sodium transport in A6 cells, Am. J. Physiol. Endocrinol. Metab. 274,E611-617 (1998).

2. B.L. Blazer-Yost, T.G. Paunescu, S.I. Helman, K.D. Lee and C.J. Vlahos, Phosphoinositide 3-kinase is required for aldosterone regulated sodium reabsorption, Am. J. Physiol. Cell Physiol. 277, C531-536 (1999).

3. B.L. Blazer-Yost, M.A. Esterman and C.J. Vlahos, Insulin-stimulated trafficking of ENaC in renal cells requires PI 3-kinase activity, Am. J. Physiol. Cell Physiol. 284, C1645-1653 (2003).

4. B.L. Blazer-Yost, M. Cox, and R. Furlanetto. Insulin and IGF1 receptor-mediated $\mathrm{Na}^{+}$transport in toad urinary bladders, Am. J. Physiol. Cell Physiol. 257, C612-620 (1989).

5. R.D. Record, M. Johnson, S. Lee and B.L. Blazer-Yost, Aldosterone and insulin stimulate amiloridesensitive sodium transport in A6 cells by additive mechanisms, Am. J. Physiol Cell Physiol. 271, C10791084 (1996).

6. B.L. Blazer-Yost, X. Liu and S.I. Helman, Hormonal regulation of ENaCs: Insulin and aldosterone, Am. J. Physiol. Cell Physiol. 274, C1373-C1379 (1998).

7. B.L. Blazer-Yost, Y. Fesseha and M. Cox, Aldosterone-mediated $\mathrm{Na}^{+}$transport in renal epithelia: Timecourse of induction of a potential regulatory component of the conductive $\mathrm{Na}^{+}$channel, Biochem. Intern. 26, 887-897 (1992).

8. B.L. Blazer-Yost, M. Butterworth, A.D. Hartman, G.E. Parker, C.J. Faletti, W.J. Els and S.J. Rhodes, Characterization and imaging of A6 epithelial cell clones expressing fluorescently labeled ENaC subunits, 
Am. J. Physiol. Cell. Physiol. 281, C624-632 (2001).

9. C.M. Canessa, J.-D. Horisberger and B.C. Rossier, Epithelial sodium channel related to proteins involved in neurodegeneration, Nature 36, 467-470 (1993).

10. C.M. Canessa, L. Schild, G. Buell, B. Thorens, I. Gautschi, J.-D. Horisberger and B.C. Rossier Amiloridesensitive epithelial $\mathrm{Na}^{+}$channel is made of three homologous subunits, Nature 367, 463-466 (1994).

11. E.N. Lingueglia, Voilley, R. Waldmann, M. Lazdunski and P. Barbry, Expression cloning of an epithelial amiloride-sensitive $\mathrm{Na}^{+}$channel: A new channel type with homologies to Caenorhabditis elegans degenerins, FEBS Lett. 318, 95-99 (1993).

12. J.H. Hanson, C. Nelson-Williams, H. Suzuki, L. Schild, R. Shimkets, Y. Lu, C. Canessa, T. Iwasaki, B. Rossier and R.P. Lifton, Hypertension caused by a truncated epithelial sodium channel subunit: genetic heterogeneity of Liddles syndrome, Nature Genet. 11, 76-82 (1995).

13. R.A. Shimkets, D.G. Warnock, C.M. Bositis, C. Nelson-Williams, J.H. Hanson, M. Schambelan, J.R. Gill, Jr., S. Ulick, R.V. Milora, J.W. Findling, C.M. Canessa, B.C. Rossier and R.P. Lifton, Liddle's syndrome: Heritable human hypertension caused by mutations in the. subunit of the epithelial sodium channel, Cell 79, 407-414 (1994).

14. S.S. Chang, S. Grunder, A. Hanukoglu, A. Rösler, P.M. Mathew, I. Hanukoglu, L. Schild, Y. Lu, R.A. Shimkets, C. Nelson-Williams, B.C. Rossier and R.P. Lifton, Mutations in subunits of the epithelial sodium channel cause salt wasting with hyperkalaemic acidosis, pseudohypoaldosteronism type 1 , Nature Genet. 12, 248-253 (1996).

15. S.D. Gründer, Firsov, S.S. Chang, N.F. Jaeger, I. Gautschi, L. Schild and B.C. Rossier, A mutation causing pseudohypoaldosteronism type 1 identifies a conserved glycine that is involved in the gating of the epithelial sodium channel, EMBO J. 16, 899-907 (1997).

16. S. S. Strautnieks, R. J. Thompson, R. M. Gardiner and E. Chung, A novel splice-site mutation in the subunit of the epithelial sodium channel gene in three pseudohypoaldosteronism type 1 families, Nature Genet. 13, 248-250 (1996).

17. I. Hajjar and T.A. Kotchen, Trends in prevalence, awarness, treatment and control of hypertension in the United States, 1988-2000, JAMA 290, 199-206 (2003).

18. V.L. Burt, P. Whelton, E.J. Roccella, C. Brown, J.A. Cutler, M. Higgins, M.J. Horan and D. Labar, The prevalence of hypertension in the US adult population, Hypertens. 25, 305-313 (1995).

19. W.J. Els and S.I.. Helman, Regulation of epithelial sodium channel densities by vasopressin signaling, Cellul. Signal. 1, 533-539 (1989).

20. Y. Marunaka, N. Hagiwara and H. Toda, Insulin activates single amiloride-blockable Na channels in a distal nephron cell line (A6), Am. J. Physiol. Renal Fluid Electrolyte Physiol. 263, F392-F400 (1992).

21. A.E. Kemendy, T.R. Kleyman and D.C. Eaton, Aldosterone alters the open probability of amilorideblockable sodium channels in A6 epithelia, Am J. Physiol. Cell Physiol. 263, C825-C837 (1992).

22. G.D. Holman and M. Kasuga, From receptor to transporter: insulin signaling to glucose transport, Diabetol. 40, 991-1003 (1997).

23. P.R. Shepherd, B.T. Nave and S. O'Rahilly, The role of phosphoinositide 3-kinase in insulin signaling, $J$. Mol. Endocrin. 17, 175-184 (1996).

24. A. Toker and L.C. Cantly, Signaling through the lipid products of phosphoinositide-3-OH kinase, Nature 387, 673-676 (1997).

25. L. del Peso, M. Gonzalez-Garcia, C. Page, R. Herrera and G. Nunez, Interleukin-3-induced phosphorylation of BAD through the protein kinase Akt, Science 278, 687-689 (1997).

26. B.M. Marte and J. Downward, PKB/Akt: connecting phosphoinositide 3-kinase to cell survival and beyond, Trends in Biol. Sci. 22, 355-358 (1997).

27. B. Cheatham, C.J. Vlahos, L. Cheatham, L. Wang, J. Blenis and C.R. Kahn, Phosphatidylinositol 3kinase activation is required for insulin stimulation of pp70 S6 kinase, DNA synthesis, and glucose transporter translocation, Mol. Cell. Biol. 14, 4902-4911 (1994).

28. J.I. Yeh, E.A. Gulve, L. Rameh and M.J. Birnbaum, The effects of wortmannin on rat skeletal muscle, $J$. Biol. Chem. 270, 2107-2111 (1995).

29. G. Sweeney, R. Somwar, T. Ramlal, P. Martin-Vasallo and A. Klip, Insulin stimulation of $\mathrm{K}^{+}$uptake into 3T3-L1 fibroblasts involves phosphatidylinositol 3-kinase and protein kinase C-zeta, Diabetologia 41, 1199-1204 (1998).

30. Y.H. Ma, H.P. Reusch, E. Wilson, J.A. Escobedo, W.J. Fantl, L.T. Williams and H.E. Ives, Activation of $\mathrm{Na}^{+} / \mathrm{H}^{+}$exchange by platelet-derived growth factor involves phosphatidylinositol 3-kinase and phosphorlipase C gamma, J. Biol. Chem. 269, 30734-30739 (1994).

31. S. Khurana, S.K. Nath, S. A. Levine, J. M. Bowser, C. Tse, M. E. Cohen and M. Donowitz, Brush border phosphatidylinositol 3-kinase mediates epidermal growth factor stimulation of intestinal $\mathrm{NaCl}$ absorption and $\mathrm{Na}^{+/} \mathrm{H}^{+}$exchange, J. Biol. Chem. 271, $9919-9927$ (1996).

32. J.M. Uribe, S.J. Keely, A E. Traynor-Kaplan and K.E. Barrett, Phosphatidylinositol 3-kinase mediates the 
inhibitory effect of epidermal growth factor on calcium-dependent chloride secretion, J. Biol. Chem. 271, 26588-26595 (1996).

33. D.R. Alessi, S.R. James, C.P. Downes, A.B. Holmes, P.R., Gaffney, C.B. Reese and P. Cohen, Characterization of a 3-phosphoinositide-dependent protein kinase which phosphorylates and activates protein kinase B $\alpha$, Curr. Biol. 7, 261-269 (1997).

34. D. Stokoe, L.R. Stephens, T. Copeland, P.R. Gaffney, C.B. Reese, G.F. Painter, A.B. Holmes, F. McCormick and P.T. Hawkins, Dual role of phosphatidylinositol-3,4,5,-trisphosphate in the activation of protein kinase B, Science 277, 567-570 (1997).

35. X. Cheng, Y. Ma, M. Moore, B.A. Hemmings and S.S. Taylor, Phosphorylation and activation of cAMPdependent protein kinase by phosphoinositide-dependent protein kinase, Proc. Natl. Acad. Sci. USA. 95, 9849-9854 (1998).

36. T. Kobayashi and P. Cohen, Activation of serum- and glucocorticoid-regulated protein kinase by agonists that activate phosphatidylinositol 3-kinase is mediated by 3-phosphoinositide-dependent protein kinase-1 (PDK1) and PDK2, Biochem. J. 339, 319-328 (1999).

37. J. Park, M.L.L. Leong, P. Buse, A.C. Maiyar, G.L. Firestone and B.A. Hemmings, Serum and glucocorticoid-inducible kinase (SGK) is a target of the PI 3-kinase-stimulated signaling pathway, EMBO J. 18, 3024-3033 (1999).

38. S. Y. Chen, A. Bhargava, L. Mastroberardino, O.C. Meijer, J. Wang, P. Buse, G.L. Firestone, F. Verrey and D. Pearce, Epithelial sodium channel regulated by aldosterone-induced protein sgk, Proc. Natl. Acad. Sci. USA 96, 2514-2519 (1999).

39. A. Naray-Fejes-Toth, C. Canessa, E.S. Cleaveland, G. Aldrich and G. Fejes-Toth, sgk is an aldosteroneinduced kinase in the renal collecting duct, J. Biol. Chem. 274, 16973-16978 (1999).

40. E. Kamynina and O. Staub, Concerted action of ENaC, Nedd4-2 and Sgk1 in transepithelial $\mathrm{Na}^{+}$ transport. Am. J. Physiol. Renal Physiol, 283, F377-F387 (2002).

41. O. Staub, S. Dho, P.C. Henry, J. Correa, T. Ishikawa, J. McGlade and D. Rotin, WWW domains of Nedd4 bind to the proline rich PY motifs in the epithelial $\mathrm{Na}^{+}$channel deleted in Liddle's syndrome, EMBOJ. 15, 2371-2380 (1996).

42. O. Staub, H. Yeger, P.J. Plant, H. Kim, S.A. Ernst and D. Rotin, Immunolocalization of the ubiquitinprotein ligase Nedd4 in tissues expressing the epithelial sodium channel (ENaC), Am. J. Physiol. Cell Physiol. 272, C1871-C1880 (1997).

43. C. Debonneville, S.Y. Flores, E. Kamynina, P.J. Plant, C. Tauxe, M.A. Thomas, C. Munster, A. Chraibi, J.H. Pratt, J-D. Horisberger, D. Pearce, J. Loffing and O. Staub, Phosphorylation of Nedd4-2 by Sgk1 regulates epithelial $\mathrm{Na}^{+}$channel cell surface expression, The EMBO J. 20, 7052-7059 (2001).

44. E. Kamynina,, C. Debonneville, M. Bens, A. Vandewalle and O. Staub, A novel mouse Nedd4 protein suppresses the activity of the epithelial $\mathrm{Na}^{+}$channel, FASEB J. 15, 204-214 (2001).

45. P.M. Synder, D.R. Olson and B.C. Thomas. Serum and glucocorticoid-regulated kinase modulates Nedd42-mediated inhibition of the epithelial $\mathrm{Na}^{+}$channel, J. Biol. Chem. 277, 5-8 (2002).

46. C. J. Faletti, N. Perrotti, S.I. Taylor and B.L. Blazer-Yost, sgk: An essential convergence point for peptide and steroid hormone regulation of ENaC-mediated $\mathrm{Na}^{+}$transport, Am. J. Physiol. Cell Physiol. 282, 494$500(2002)$.

47. P. Wulff, V. Vallon, D.Y. Huang, H. Volk1, F. Yu, K. Richter, M. Jansen, M. Schlunz, K. Klingel, J. Loffing, G. Kauselmann, M.R. Bosl, F. Lang and D. Kuhl, Impaired renal $\mathrm{Na}^{+}$retention in the sgk1knockout mouse, J. Clin. Invest. 110, 1262-1268 (2002).

48. D. Alvarez de la Rosa and C. Canessa, Role of SGK in hormonal regulation of epithelial sodium channel in A6 cells. Am. J. Physiol. Cell Physiol. 284, C404-C414, (2003)

49. D. Alvarez de la Rosa, T. Coric, N. Todorovic, D. Shao, T. Wang and C. Canessa, Distribution and regulation of expression of serum- and glucocorticoid-induced kinase-1 in the rat kidney, J. Physiol. 551, 455-466 (2003).

50. X. Cheng, Y. Ma, M. Moore, B.A. Hemmings and S.S. Taylor, Phosphorylation and activation of cAMPdependent protein kinase by phophoinositide-dependent protein kinase, Proc. Natl. Acad. Sci. USA 95, 9849-9854 (1998).

51. M.J. Moore, J.R. Kanter, K.C. Jones and S.S. Taylor, Phosphorylation of the catalytic subunit of protein kinase A: autophosphorylation versus phosphorylation by phosphoinositide-dependent kinase-1, J. Biol. Chem. 277, 47878-47884 (2002).

52. N. Perrotti, R.A. He, S A. Phillips, C.R. Haft and S.I. Taylor, Activation of serum- and glucocorticoidinduced protein kinase (sgk) by cyclic AMP and insulin, J. Biol. Chem. 276, 9406-9412 (2001).

53. C. Nofziger and B.L. Blazer-Yost, ADH-stimulated $\mathrm{Na}^{+}$transport: Interaction between the cAMP/PKA and phosphoinositide signaling pathways, 2003 International Cell Symposium, Dayton OH (Sep 20-25, 2003). 
54. D. Yoo, B.Y. Kim, C. Campo, L. Nance, A. King, D. Maouyo and P.A. Welling, Cell surface expression of the ROMK (Kir 1.1) channel is regulated by the aldosterone-induced kinase, sgk-1, and protein kinase A, J. Biol. Chem. 278, 23066-23075 (2003). 